\title{
A View On Employee Attrition
}

\author{
Dr .Swathi.S
}

\author{
Assistant professor, YuvarajaCollege,Mysuru, Mysuru \\ DOI: 10.29322/IJSRP.10.03.2020.p9905 \\ http://dx.doi.org/10.29322/IJSRP.10.03.2020.p9905
}

\begin{abstract}
Attrition is the most common phenomena found in the private sector. when it come to IT companies attrition has become a disease in which all the IT companies are trying to get the best solution for that problem. In this paper an attempt is made by taking forty convenient sampling from IT company to identify the reason for attrition and ways to reduce attrition are discussed in the paper.
\end{abstract}

Index Terms- Attrition, salary, Human resource, IT employees and job expectation.

\section{INTRODUCTION}

A ttrition is an alarming concern for all the organizations across various sectors. Anything that involves manpower would be affected by employee attrition. Whenever employees leave an organization, the knowledge and intellect also leaves. Human Resource practitioners can try and capture the knowledge and intellect of the talent, however, this is easy said than done. Nowadays, the importance and relevance of the employees is well understood by the organizations and hence the focus is on understanding the key factors that affects employee attrition. The aim of this research is to understand and identify various researches conducted on employee attrition across sectors. For the same, the literature starting from 1955-2014 is studied. The research has highlighted the factors like dissatisfaction with compensation offered, payment below prevailing market rate and inadequacy in the internal and external equity, Inappropriate Reward and recognition, toxic work environment \&incompatible work culture, employee attitude, Insufficient support, unsatisfactory relationships with superior, colleagues and subordinates (work relationship), and inadequate opportunities for growth, hiring practices, and managerial style, which affect employee attrition. Understanding attrition is imperative for every organization. Mere recognition of factors would not do any better, both for employees as well as employer. This study focuses on compiling the factors that affect attrition and has a further scope where these factors can be empirically tested in different sectors and recommendations can be incorporated as to observe the difference in the attrition rate

\section{ATTRITION}

Attrition can be understood as the irregular and overwhelming, but normal decrease of workforce due to resignations, retirement, sickness, or death (as cited in www.citehr.com, 2010). It signifies the rate of change in the working staff of a concern during a definite period. In other words, it refers to the shifting of workforce into and out of an organization. Most of the HR managers feel that retaining their talented workforce is one of the most challenging tasks, and it is becoming more and more difficult for them to tackle the problem of excessive turnover in their companies and to find ways of retaining their staff.

\section{ATTRITION RATE.}

There is no standard formula to calculate the attrition rate of a company. This is because of certain factors (Dev, 2005), such as:

1. The employee base changes each month. So if a company has 1,000 employees in April 2004 and 2,000 in March 2005 , then they may take their base as 2,000 or as 1,500 (average for the year). If the number of employees who left is 300 , then the attrition figure could be $15 \%$ or $20 \%$ depending on what base is considered.

2. Many firms may not include attrition of new graduates who leave because of higher studies, especially within three months of joining.

3. In some cases, attrition of poor performers may also not be treated as attrition.

Employee Attrition

$$
\begin{aligned}
& =\frac{\text { No. of Employee who left in the year }}{\text { Average Number of Employees in an organization in a year }} \\
& \times 100
\end{aligned}
$$

Thus, if the company had 1,000 employees in April 2004, 2,000 in March 2005, and 300 quit in the year, then the average employee strength is 1,500 and attrition is $100 \times(300 / 1500)=20$ percent. Formula to calculate employee attrition rate (Source: TVS Infotech as cited in Dev, 2005).

There are various other types of attrition that should be taken into account (Dev, 2005).

These are:

1. Fresher attrition tells the number of fresher's who left the organization within one year. It tells how many are using the company as a springboard or a launch pad.

2. Infant mortality is the percentage of people who left the organization within one year. This indicates the ease with which people adapt to the company.

3. Critical resource attrition tells the attrition in terms of key personnel like senior executives leaving the organization. 
4. Low performance attrition tells the attrition of those who left due to poor performance. According to studies conducted by Hay Group, the cost of attrition of an employee can be higher than apparent.

March 1, 2018.In an article in Forbes, points out the Mercer survey highlights that no fewer than $54 \%$ of Indian workers are seriously considering leaving their jobs, and that figure spikes to
$66 \%$ in the 16-24 year age bracket. It also points out the other independent studies "confirm the correlation between intention to leave and actual turnover." What puzzling is that the people considering leaving are not even highly disengaged employees.76\% of Indians surveyed reported satisfaction with their jobs and $75 \%$ with their organizations.

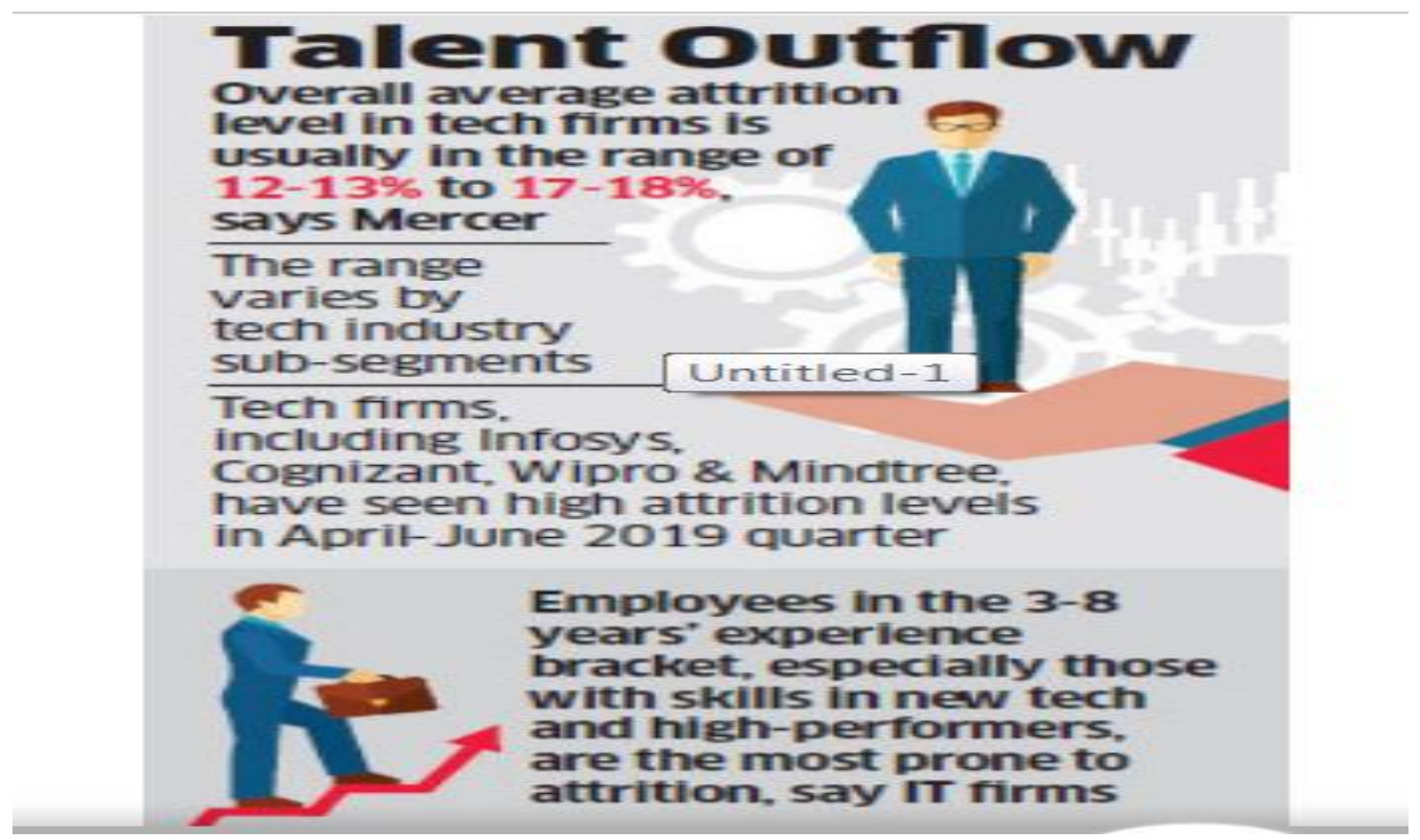

Sourced from:https://economictimes.indiatimes.com/tech/ites/it-companies-go-all-out-to-stop-attrition-of-skilled-youngstaff/articleshow/70693130.cms?from $=\mathrm{mdr}$

\section{RESEARCH METHODOLOGY.}

Descriptive method has been used in the paper.

\section{SCOPE OF THE STUDY.}

The scope of the study is confined to the VST company located in electronic city Bangalore. More focus on reason for attrition.

\section{SOURCE OF DATA.}

Data was collected from both primary and secondary sources. Primary data was collected through structured questionnaire methods. The secondary data was extracted from different publishers and websites.

\section{SAMPLE DESIGN.}

Non Probability sampling technique was used for the paper. Convenient random sampling had been used.

IV. SAMPLE SIZE.

Forty convenient samples were taken for the study.
Table : 1

\begin{tabular}{|l||l||}
\hline Reliability Statistics \\
\hline \hline $\begin{array}{l}\text { Cronbach's } \\
\text { Alpha }\end{array}$ & N of Items \\
\hline \hline .738 & 10 \\
\hline
\end{tabular}

The Table 1.shows the value of Cronbach's Alpha reliability test for the questionnaire employee engagement comprising 4 statements. The alpha coefficient for the four items is 0.738 , suggesting that the items have relatively high internal consistency.

(Note that a reliability coefficient of 0.70 or higher is considered "acceptable" in most social science research situations.) 
Table: 2

\begin{tabular}{|c|c|c|c|c|}
\hline \multicolumn{5}{|c|}{ Descriptive Statistics } \\
\hline Sl.No & $\begin{array}{|lr|}\text { Reasons } & \text { for } \\
\text { change } & \text { of } \\
\text { job } & \end{array}$ & $\mathbf{N}$ & Mean & Std. Deviation \\
\hline 1 & $\mid \begin{array}{l}\text { Able to get } \\
\text { Better Salary } \\
\text { Elsewhere }\end{array}$ & 40 & 3.44 & 1.095 \\
\hline 2 & \begin{tabular}{|l|} 
Having \\
Issues with \\
Co-worker
\end{tabular} & 40 & 1.64 & .986 \\
\hline 3 & $\begin{array}{l}\text { Working in } \\
\text { Shifts } \\
\text { becomes } \\
\text { problematic }\end{array}$ & 40 & 1.67 & 1.108 \\
\hline 4 & $\mid \begin{array}{lr}\text { Better } & \text { Job } \\
\text { Opportunities } \\
\text { elsewhere }\end{array}$ & 40 & 2.95 & 1.075 \\
\hline 5 & $\begin{array}{l}\text { Problems } \\
\text { with manager } \\
\text { and higher } \\
\text { authority }\end{array}$ & 40 & 1.38 & .847 \\
\hline 6 & $\begin{array}{l}\text { Health issues } \\
\text { become } \\
\text { major } \\
\text { constraint }\end{array}$ & 40 & 1.56 & .821 \\
\hline 7 & \begin{tabular}{|ll||} 
My & Job \\
Expectation \\
is & not \\
matched &
\end{tabular} & 40 & 3.10 & 1.273 \\
\hline 8 & $\begin{array}{|ll|}\text { Difficult } & \text { to } \\
\text { balance } & \\
\text { family } & \\
\text { pressure } & \end{array}$ & 40 & 2.74 & 1.517 \\
\hline 9 & $\left|\begin{array}{|rr}\text { Difficult } & \text { to } \\
\text { adjust } & \text { with } \\
\text { local Culture }\end{array}\right|$ & 40 & 1.97 & 1.367 \\
\hline 10 & \begin{tabular}{|l|} 
Existence of \\
inadequate \\
career \\
prospects
\end{tabular} & 40 & 2.38 & 1.138 \\
\hline & $\begin{array}{l}\text { Valid } \mathrm{N} \text { (list } \\
\text { wise) }\end{array}$ & 40 & & \\
\hline
\end{tabular}

Sourced from : Primary data.

From the above Table 2, it can be seen that there are 10 reasons for change of job for which the mean and standard deviation was tabulated. The most important reason for change of job will have highest mean. Accordingly, the prominent statements specifying the reasons for change of job were:
Able to get better Salary elsewhere 3.44, employees give more importance to monetary rewards.

My job expectation is not matched 3.10, if employee expectation are not full filled than employees like to change the job.

Better Job Opportunities elsewhere 2.95, Young IT employees also look out more of mobility and Challenges in the job.so this leads to change of job.

Difficult to balance family pressure 2.61.when the employees feel unable to balance family pressure they like the change the job.

Existence of inadequate career prospects 2.38, all employees need career growth in the job if there is no growth in the job.

\section{DISCUSSION AND CONCLUSION:}

Employees are in the age group of twenty three to thirty years only, when you have very young professionals. They look out for the different needs. It becomes very much essential for them to Employees start to look out for better monetary rewards. They are ready to go any were to make money. Employees always come with different types of expectation understanding them becomes a major challenge for the employers. All employees need growth when they are not given opportunity they start to look for another job was their need is fulfilled. When employees face personal problems automatically they cannot perform better in the job so this condition somehow leads to change of job. Claiming the career ladder becomes very much essential to all professional so the amount of initiation taken to do so will lead to the change of job.

If IT employees are given more importance on cross cultural training giving importance to the job fit, understanding the young professional needs, providing the young employees more opportunity in decision making, making employees more valued in the job, Helping the employees to learn new skills , making the job stress free, having the open system to share the information, having the cordial relationship in the work environment will lead reduction in the attrition level.

The concept of attrition has been studied for almost three to four decade but they are not able to give the golden button solution for such problems .so the existence of attrition becomes one of the major discussed and research topic in the field of human resource management.

\section{REFERENCES}

[1] Abbasi, S. and Hollman, K. (2000), "Turnover: the real bottomline", Public Personnel Management, Vol. 29 No. 3, pp. 333- 342

[2] Adhikari, A, (2009), Factors Affecting Employee Attrition: A Multiple Regression Approach, The Icfaian Journal of Management Research, Vol. VIII, No. 5,PP,38-43

[3] Arthur, J. B. (1994). Effects of human resource systems on manufacturing performance and turnover. Academy of Management Journal, 37, 670-687

[4] Arora, A. Arunachalam,V. Asundi,J. and Fernandes,R. (2001), The Indian software services industry Research Policy 30, pp.1267-1287.

[5] Archita Banerjee. (2019). "FAILURE OF EMPLOYEE RETENTION AND ITS CONSEQUENCES ON ORGANISATION THROUGH CONTENT ANALYSIS." International Journal of Research - Granthaalayah, 7(3), 200207. https://doi.org/10.5281/zenodo.2631378. 
[6] Attrition's a Blessing for ITeS Companies - DevinaSengupta, Economic times. (August 9, 2011)

[7] Antony Joe Raja,AnbuRanjith Kumar ((2016),A STUDY TO REDUCE EMPLOYEE ATTRITION IN IT INDUSTRIES,International Journal of Marketing and Human Resource ManagementVolume 7, Issue 1, JanuaryApril (2016), pp. 01-14

[8] Brayfield, A.H. and Crockett, W.H. (1955), "Employee attitudes and employee performance", Psychological bulletin, Vol. 52 No. 5, pp. 396-405

[9] Brijesh Kishore Goswami, SushmitaJha (-2012),Attrition Issues and Retention Challenges of Employees,International Journal of Scientific \& Engineering Research Volume 3, Issue 4,ISSN 2229-5518.

[10] Dr. K. BalajiMathimaran $\alpha$ \& Prof. Dr. A. Ananda Kumar (2017),Employee Retention Strategies - An Empirical Research,Global Journal of Management and Business Research: E Marketing,Volume 17 Issue 1 Version 1.0,Online ISSN: 2249-4588 \& Print ISSN: 0975-5853

[11] Chakravorty, B. (2005), "BPO E-Sat 2005", Dataquest, November 15, pp. 22-28, available at www.iseva.com/news-events/downloads/iSeva-Thepreferred-employer.pdf.Last accessed on February 06, 2010.

[12] Chowdhury Abdullah Al Mamun and Md. NazmulHasan (2017). Factors affecting employee turnover and sound retention strategies in business organization: a conceptual view. Problems and Perspectives in Management, 15(1), 63-71. doi:10.21511/ppm.15(1).2017.06

[13] Deepa and Stella(2012), Employee turnover in "IT" industry with special reference to Chennai city -an exploratory study, ZENITH International Journal of Multidisciplinary Research Vol.2 Issue 7, ISSN 2231 -5780

[14] Dev, S. (2005); Calculating Employee Attrition; 22nd August 2005, para3-4, 9-10.Retrieved

from (http://www.expresscomputeronline.com/20050822/technologylife01.shtml Retrieved on 30th June 2009).

[15] Ho, J.S.Y Downe, A.G and Loke,S-P. (2010), "Employee attrition in the Malaysian service industry: push and pull factors", The IUP Journal of Organizational behavior, Vol 9 Nos 1\&2, pp. 16-31, January and April 2010.

[16] Frye, Alex; Boomhower, Christopher; Smith, Michael; Vitovsky, Lindsay; and Fabricant, Stacey (2018) "Employee Attrition: What Makes an Employee Quit?," SMU Data Science Review: Vol. 1 : No. 1 , Article 9.

Available at: https://scholar.smu.edu/datasciencereview/vol1/iss1/9

[17] Herman, R.E. (1999), "Hold on to the people you need", HR Focus Special Report on Recruitment and Retention, June, Supplement 11

[18] Ms. MishaMehta,ManishMadan (2017),A Comprehensive Literature Review on Employee Attrition,International Journal of Enhanced Research in
Management \& Computer Applications.SSN: 2319-7471, Vol. 6 Issue 10, October-2017, Impact Factor: 3.578

[19] LathaLavanya (2017),A Study on Employee Attrition: Inevitable yet Manageable,International Journal of Business and Management Invention, Volume 6 Issue 9,PP-38-50.

[20] Raon V.S.P. - Human Resource Management, Second Edition, Excel Books, NewDelhi.

[21] RuchiraDobhal,DrAkankssha Nigam (2018),Employee Attrition and Employee Satisfaction: A Study of H.R., Performance Appraisal \& Training Practices in Defence PSUs in India,IOSR Journal of Business and Management, Volume 20, Issue 2. PP 01-27,ISSN: 2319-7668.

[22] Dr.D.Rajasekar and Dr.B. Venkateswara Prasad (2017), Employee Job Satisfaction and Intention to Attrition-An Empirical Analysis, International Journal of Mechanical Engineering and Technology 8(12), , pp. 856-861.

[23] LichiaYiu1, Raymond Saner (2014),Talent Attrition and Retention: Strategic Challenges for Indian Industries in the Next Decade,Elite Research Journal of Accounting and Business Management Vol. 2(1) pp. 1- 9.

[24] 'Firms tempt talents with Golden Hellos'- Writankar Mukherjee, Economic times. (May 23, 2010).

[25] SabithaNiketh(2008), Attrition: A Global Problem ,HRM Review, March 2008 Issue, Pg. no. 64-67, ICFAI University Press, Hyderabad

[26] Ms. Shaveta Gupta*, Dr. Sukhmani*, Ms. HarsimranKaur (2011),RETENTION MANAGEMENT AND COST OF ATTRITION: A KEYWORD TO PROFITABILITY,GIAN JYOTI E-JOURNAL, Vol. 1, Issue 1 (Oct-Nov 2011)

[27] Sreenivas Mahesh (2017),Employee Attrition Models- A ConceptualFramework,International Journal of Engineering, Management \& Sciences (IJEMS),Volume-4, Issue-4,ISSN-2348 -3733

[28] N.Silpa (2015),A Study on Reasons of Attrition and Strategies for Employee Retention,Journal of Engineering Research and Applications,ISSN: 22489622, Vol. 5, Issue 12, (Part - 1) December 2015, pp.57-60

[29] https://thehrmonks.com/what-is-the-attrition-rate-in-indian-industries-andthe-reasons-behind-the-turnover/

\section{AUTHORS}

First Author - Dr .Swathi.S, Assistant professor, YuvarajaCollege,Mysuru, Mysuru 